\title{
Spinone Italiano
}

National Cancer Institute

\section{Source}

National Cancer Institute. Spinone Italiano. NCI Thesaurus. Code C53892.

The Spinone Italiano, also known as the Spinone, Italian Spinone, or Italian Griffon is a large, rugged dog of distinctive appearance. It has a long head, with hang ing ears. Its body is strong-boned, of square build, and with a deep chest. Its coat protects it from the water and freezing temperatures. Height: 22 1/2-27 1/2 inches. Weight: 61-85 pounds. 